\title{
Equipe Multiprofissional em Saúde da Família: do Documental ao Empírico no Interior da Amazônia
}

\author{
Multidisciplinary Teamwork in Family \\ Health: from a Documental to an Empirical \\ Approach in the Amazon
}

Rodrigo Otávio Moretti-Pires ${ }^{I}$ Dalvan Antônio de Campos ${ }^{I}$

\section{PALAVRAS-CHAVE \\ - Saúde da Família. \\ - Equipe de Assistência ao Paciente. \\ - Pesquisa Qualitativa.}

\section{ABSTRACT}

The Family Health Strategy (FHS) in Brazil has employed multidisciplinary teams, precisely for this health care model to allow linking knowledge in the provision of care. Objective: This study's objective was to investigate the perceptions of physicians, nurses, and dentists concerning the functioning of multidisciplinary family health teams in the municipality (county) of Coari, Amazonas State, Brazil. Methods: This was a qualitative study with a semi-structured questionnaire applied through individual interviews with all the primary care professionals in the municipality, compared to interviews with physical therapists and psychologists from secondary care services, analyzed through dialectic hermeneutics. Results: Except for the psychologists' discourse, the perceptions by physicians and other family health professionals revealed weaknesses in the development of a joint intervention project, particularly necessary for the FHS, thereby revealing that multidisciplinary teamwork only occurs in theory and not according to the underlying logic of the work process in family health care.

\begin{abstract}
As equipes multiprofissionais foram adotadas na Estratégia de Saúde da Família (ESF), justamente para que este modelo de atenção permita a articulação entre saberes na prática da assistência à saúde. Objetivo: Investigar a percepção dos médicos, enfermeiras e odontólogos sobre o funcionamento de equipes multiprofissionais na Saúde da Família do município de Coari (AM). Métodos: Pesquisa qualitativa, com roteiro semiestruturado, aplicado em entrevistas individuais a todos os profissionais da atenção primária do município, comparadas a entrevistas com fisioterapeutas e psicólogos de serviço secundário, analisadas à luz da hermenêutica dialética. Resultados: Com exceção do discurso dos psicólogos, a percepção dos médicos e demais profissionais de Saúde da Família demonstra a fragilidade na construção do projeto de intervenção conjunta, necessário principalmente à ESF, apresentando a perspectiva de que o trabalho multiprofissional se dá apenas em teoria e não na lógica que rege o processo de trabalho.
\end{abstract}




\section{INTRODUÇÃO}

Em artigo recente na revista Interface - Comunicação, Educação e Saúde, Moretti-Pires ${ }^{1}$ defende que a Estratégia de Saúde da Família se pauta por uma perspectiva ampla de saúde, conceito cuja operacionalização se aproxima da teoria da complexidade de Edgar Morin. Nesse artigo, o autor analisa informações empíricas sobre a formação reducionista do médico, do enfermeiro e do odontólogo, que é incoerente com a perspectiva complexa do modelo de atenção em Saúde da Família. Se achados semelhantes seriam encontrados ao se investigar a atuação dos acadêmicos formados por este modelo durante sua vida profissional em Saúde da Família frente ao paradigma da complexidade de Morin é uma indagação que serviu de premissa para a presente investigação.

Na história do Brasil, as Políticas de Saúde se deram num crescendo, até a inserção de princípios na Constituição Nacional como o direito de todos os cidadãos à saúde como um dever do Estado, por meio do Sistema Único de Saúde (SUS)². A universalização do acesso aos serviços promoveu avanços em termos dos padrões de saúde da população. No entanto, stricto sensu, os princípios doutrinários do SUS foram corrompidos na construção do Sistema, que, de fato, não atingiu um estágio de maturidade em que se tornam visíveis os princípios norteadores e filosóficos do SUS².

Em função deste contexto, um amplo debate entre governo, intelectuais e sociedade foi promovido na década de 1990, ocasionando a reorganização do processo de produção dos serviços de saúde de maneira profunda e a estruturação do sistema em si. Este processo, que primou pelo refinamento do SUS existente em consonância com as diretrizes e princípios do SUS desejado, culminou na criação do Programa de Saúde da Família, posteriormente modificado para Estratégia de Saúde da Família (ESF). Essa estratégia visa à idealização e à valorização da prestação de serviços públicos de saúde, articulada junto à comunidade, enfocando não apenas ações curativas e centradas na doença, mas, em especial, ações que incidissem sobre determinantes de saúde e promoção de saúde.

Nesta nova abordagem da Atenção Primária no Brasil, as equipes devem atuar integrando as diversas competências e categorias profissionais que as compõem; primar pela ação articulada com setores que medeiam e interferem nos determinantes socioculturais do processo saúde-doença, fugindo da lógica do atendimento curativo e apenas da demanda na Unidade de Saúde da Família; e ter foco na horizontalidade, vínculo e corresponsabilidade pelas ações junto aos usuários do sistema. Isto ressignifica o papel do sistema, delegando-lhe uma importância que difere sobremaneira do enfoque tradicional, em que o usuário era apenas o paciente, passivo, em busca dos serviços que os profissionais de saúde ofereciam por se constituírem como conhecedores do processo saúde-doença em suas fragmentadas especialidades ${ }^{3}$.

Neste contexto de transformação - sendo o papel dos profissionais mais do que o de prestador de serviços junto a ações para a cura e a reabilitação —, a nova política de saúde exige um profissional adequado à consecução dos princípios do SUS na prática diária. E essa exigência não se refere apenas às novas categorias profissionais, como os agentes comunitários de saúde. Refere-se particularmente às categorias tradicionais, como a Enfermagem, assim como àquelas de cunho liberal, como a Medicina e a Odontologia ${ }^{4}$.

Machado 5 aponta fragilidades quanto ao recurso humano no SUS durante seu processo de implementação. Em relação à Saúde da Família, trabalho em equipe significa interação entre os diversos profissionais, um dos pilares deste modelo de atenção, orientado à integralidade nos cuidados de saúde pautada na relação entre a complementaridade de trabalhos e a interação dos profissionais ${ }^{6-8}$.

Em 2006, o Ministério da Saúde institui a Portaria nº 648, que torna a Saúde da Família a estratégia prioritária na organização da atenção à Saúde. O conceito de Atenção Básica inserido neste instrumento legal se fundamenta numa visão ampla do processo saúde-doença, preconizando "viver de modo saudável"9 (p.1), considerando "o sujeito em sua singularidade, na complexidade, na integralidade e na inserção sociocultural e busca a promoção de sua saúde, a prevenção e tratamento de doenças e a redução de danos ou de sofrimentos" ${ }^{\prime \prime}$ (p.1).

Diante das singularidades da ESF como modelo reorientador do SUS, o presente trabalho se propõe a analisar o trabalho multiprofissional em Saúde da Família num contexto no interior da Amazônia.

\section{Percurso Metodológico}

Trata-se de um estudo pautado em metodologia qualitativa, abordagem que se baseia na busca do entendimento e da compreensão de como se dá determinado contexto, numa perspectiva de vivência e experiência pessoal de cada um dos sujeitos envolvidos, valorizando as características e dinâmicas de determinado fenômeno sem a prerrogativa da generalização ${ }^{10}$. Estudos qualitativos têm a capacidade de incorporar significado e intenção aos atos, às relações e às estruturas sociais, sendo essas últimas tomadas tanto no seu advento como na sua transformação, como construções humanas significativas, na tentativa de compreender um problema da perspectiva dos sujeitos que o vivenciam ${ }^{10,11}$.

O estudo foi conduzido no município de Coari, região do Médio Solimões, situado geograficamente no centro do Estado do Amazonas, a 363 quilômetros da cidade de Manaus. Nes- 
te município existem 11 unidades de Saúde da Família, uma para cada equipe, com uma cobertura de $100 \%$ da população urbana. Apesar de inicialmente se utilizar a representação de que falta infraestrutura no interior do Amazonas, no ano de 2008 o Sistema de Saúde do município de Coari contava com 11 unidades de Saúde da Família para as 11 equipes de Saúde da Família, duas unidades fluviais de atenção, um hospital de adscrição regional e um campus avançado da Fundação de Medicina Tropical. O SUS possui um capital humano composto por 28 médicos, 35 enfermeiros, 14 odontólogos, 4 nutricionistas, 4 psicólogos, 3 assistentes sociais, 4 fisioterapeutas e 223 agentes comunitários de saúde, dos quais 120 atuam na zona urbana.

Foi empregado um roteiro semiestruturado para entrevistas individuais, com questões que se referiam aos aspectos de como se deu a formação universitária para o trabalho multiprofissional, como este funciona no trabalho diário em Saúde da Família, o lidar com esta temática e sobre as ações individuais e da equipe no manejo das dinâmicas dos relacionamentos profissionais.
As entrevistas foram realizadas nas unidades de Saúde da Família, em salas oferecidas pela própria equipe. Foram utilizadas como critérios de inclusão dos sujeitos as seguintes características: (1) profissionais que trabalhassem na atenção primária com foco na ESF; (2) a UBS analisada deveria estar em funcionamento há pelo menos quatro anos. A inadequação de um desses critérios excluiu o participante da pesquisa.

Para estabelecer um parâmetro de comparação, entrevistaram-se todos os fisioterapeutas e psicólogos do Hospital Regional de Coari, uma vez que os primeiros têm formação tradicional focada na cura e reabilitação, enquanto os últimos são formados em temas complexos da vida humana, além do biológico.

A Tabela apresenta as características dos sujeitos entrevistados.

As informações foram registradas por gravadores e transcritas na íntegra. Os passos metodológicos seguintes foram a leitura exaustiva e a categorização dos dados com base nas reincidências de informações entre os depoimentos dos diversos sujeitos ${ }^{11}$. Em seguida, a análise buscou categorias de discursos com o mesmo tema, a partir da perspectiva dos profis-

\begin{tabular}{|c|c|c|c|c|c|c|c|c|c|c|}
\hline 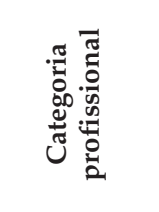 & $\begin{array}{l}\text { ڤ્㐅 } \\
\text { ผे }\end{array}$ & 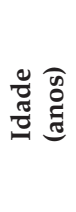 & 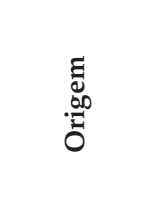 & 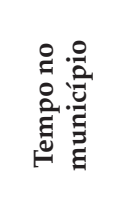 & 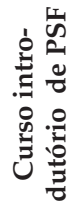 & 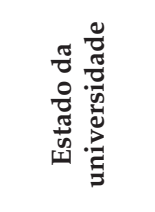 & 窇 & 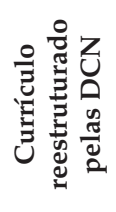 & 胥 & 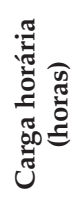 \\
\hline Odontólogo & $\mathrm{F}$ & 28 & São Paulo & 2 anos & Não & São Paulo & Pública & Sim & $4.020,00$ & 40 \\
\hline Odontólogo & $\mathrm{M}$ & 26 & Amazonas & 6 meses & Não & Amazonas & Privada & Não & $4.020,00$ & 40 \\
\hline Odontólogo & $\mathrm{M}$ & 32 & Amazonas & 1 ano & Não & Amazonas & Pública & Sim & $4.020,00$ & 40 \\
\hline Odontólogo & $\mathrm{M}$ & 31 & Bahia & 5 anos & Não & Bahia & Privada & Não & $4.020,00$ & 40 \\
\hline Odontólogo & $\mathrm{M}$ & 55 & Amazonas & 30 anos & Não & Amazonas & Pública & Não & $4.020,00$ & 40 \\
\hline Enfermeiro & $\mathrm{F}$ & 23 & Amazonas & 2 anos & Não & Amazonas & Pública & Sim & $4.020,00$ & 40 \\
\hline Enfermeiro & $\mathrm{F}$ & 23 & Amazonas & 2 anos & Não & Amazonas & Pública & Sim & $4.020,00$ & 40 \\
\hline Enfermeiro & $\mathrm{F}$ & 26 & Amazonas & 2 anos & Não & Amazonas & Pública & Sim & $4.020,00$ & 40 \\
\hline Enfermeiro & $\mathrm{F}$ & 28 & Amazonas & 2 anos & Não & Amazonas & Pública & Sim & $4.020,00$ & 40 \\
\hline Enfermeiro & $\mathrm{F}$ & 32 & São Paulo & 4 anos & Não & São Paulo & Privada & Não & $4.020,00$ & 40 \\
\hline Enfermeiro & $\mathrm{F}$ & 31 & São Paulo & 6 anos & Não & Rio Janeiro & Pública & Não & $4.020,00$ & 40 \\
\hline Enfermeiro & $\mathrm{F}$ & 35 & Amazonas & 10 anos & Não & Amazonas & Pública & Não & $4.020,00$ & 40 \\
\hline Enfermeiro & $\mathrm{F}$ & 33 & Amazonas & 3 anos & Não & Acre & Pública & Não & $4.020,00$ & 40 \\
\hline Enfermeiro & $\mathrm{F}$ & 25 & Acre & 4 anos & Não & Acre & Pública & Não & $4.020,00$ & 40 \\
\hline Enfermeiro & $\mathrm{F}$ & 22 & Acre & 2 anos & Não & Acre & Pública & Não & $4.020,00$ & 40 \\
\hline Enfermeiro & $\mathrm{F}$ & 23 & Pará & 1 ano & Não & Pará & Pública & Sim & $4.020,00$ & 40 \\
\hline Médico & $\mathrm{M}$ & 45 & Bolívia & 6 meses & Não & Bolívia & Pública & N.A. & $9.000,00$ & 40 \\
\hline Médico & $\mathrm{M}$ & 30 & Goiás & 3 anos & Não & Amazonas & Pública & Não & $9.000,00$ & 40 \\
\hline Médico & $\mathrm{M}$ & 29 & Amazonas & 3 anos & Não & Amazonas & Pública & Não & $9.000,00$ & 40 \\
\hline Médico & $\mathrm{M}$ & 28 & Amazonas & 4 meses & Não & Amazonas & Pública & Sim & $9.000,00$ & 40 \\
\hline
\end{tabular}


(conclusão)

\begin{tabular}{|c|c|c|c|c|c|c|c|c|c|c|}
\hline 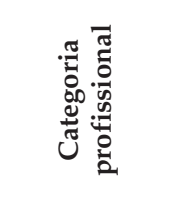 & ڤ્㐅ે & 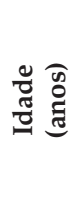 & ప్ & 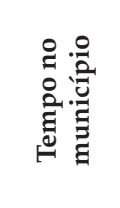 & 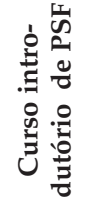 & 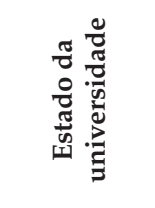 & 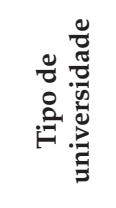 & 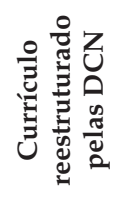 & 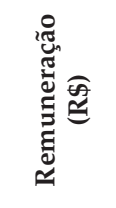 & 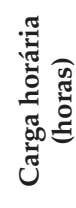 \\
\hline Médico & $\mathrm{M}$ & 31 & Amazonas & 1 ano & Não & Amazonas & Pública & Sim & $9.000,00$ & 40 \\
\hline Médico & $\mathrm{M}$ & 31 & Amazonas & 1 ano & Não & Amazonas & Pública & Sim & $9.000,00$ & 40 \\
\hline Médico & $\mathrm{M}$ & 32 & Minas Gerais & 6 meses & Não & Rio Janeiro & Pública & Sim & $9.000,00$ & 40 \\
\hline Médico & $\mathrm{M}$ & 36 & Sergipe & 6 meses & Não & Amazonas & Pública & Sim & $9.000,00$ & 40 \\
\hline Médico & $\mathrm{M}$ & 38 & Acre & 6 meses & Não & Amazonas & Pública & $\operatorname{Sim}$ & $9.000,00$ & 40 \\
\hline Médico & $\mathrm{M}$ & 33 & Rondônia & 7 meses & Não & Amazonas & Pública & Não & $9.000,00$ & 40 \\
\hline Médico & $\mathrm{M}$ & 32 & Rondônia & 6 meses & Não & Amazonas & Pública & Não & $9.000,00$ & 40 \\
\hline Médico & $\mathrm{F}$ & 28 & Rondônia & 1 anos & Não & Amazonas & Pública & Não & $9.000,00$ & 40 \\
\hline Fisioterapeuta & $\mathrm{F}$ & 26 & Amazonas & 4 anos & N.A. & Pará & Privada & N.A. & $2.300,00$ & 20 \\
\hline Fisioterapeuta & $\mathrm{F}$ & 27 & Amazonas & 4 anos & N.A. & Amazonas & Privada & N.A. & $2.300,00$ & 20 \\
\hline Fisioterapeuta & $\mathrm{F}$ & 25 & Pará & 1 ano & N.A. & Pará & Privada & N.A. & $2.300,00$ & 20 \\
\hline Fisioterapeuta & $\mathrm{M}$ & 22 & Amazonas & 1 ano & N.A. & Amazonas & Privada & N.A. & $2.300,00$ & 20 \\
\hline Psicólogo & $\mathrm{F}$ & 25 & Amazonas & 1 ano & N.A. & Amazonas & Pública & N.A. & $2.300,00$ & 20 \\
\hline Psicólogo & $\mathrm{F}$ & 24 & Amazonas & 1 ano & N.A. & Amazonas & Privada & N.A. & $2.300,00$ & 20 \\
\hline Psicólogo & $\mathrm{F}$ & 27 & Amazonas & 1 ano & N.A. & Amazonas & Privada & N.A. & $2.300,00$ & 20 \\
\hline Psicólogo & $\mathrm{F}$ & 29 & Amazonas & 5 anos & N.A. & Amazonas & Privada & N.A. & $2.300,00$ & 20 \\
\hline
\end{tabular}

Legenda: N.A. — Não se aplica; DCN — Diretrizes Curriculares Nacionais; F — feminino; M — masculino.

sionais de saúde inseridos na ESF sobre o funcionamento e o cotidiano. Após esta fase interpretativa, realizou-se a busca de contradições e coerências, de forma que o processo de análise se fundamentou na hermenêutica dialética ${ }^{10}$, utilizando como fundamentação teórica os documentos oficiais que definem os pressupostos do trabalho em Saúde da Família dentro da Política Nacional de Atenção Básica ${ }^{6}$. Cabe registrar que, para fins da elaboração do presente manuscrito, foram selecionadas as falas que de maneira mais completa emblematizavam o pensamento reincidente para cada categoria encontrada, já que a inserção de todas as considerações dos entrevistados comprometeria o artigo, em função do volume de material existente.

Os entrevistados foram recrutados individualmente, mediante contato com um dos pesquisadores em seus serviços. Todos os entrevistados participaram após explicação, compreensão, registro formal do termo de consentimento livre e esclarecido, em duas vias (uma para o pesquisador e outra para o entrevistado). $\mathrm{O}$ presente estudo respeitou as normas de pesquisa envolvendo seres humanos com base na Resolução n 196/96 do Conselho Nacional de Saúde, sendo aprovado pelo Comitê de Ética em Pesquisa da Universidade Federal de Santa Catarina - Projeto "Saúde da Família no interior do Estado do Amazonas e a operacionalização dos princípios do SUS" (Protocolo ético 121/2009).

\section{RESULTADOS}

Após tratamento das entrevistas, dado o vasto conteúdo empírico encontrado, optou-se por apresentar o conteúdo interpretativo do material empírico nos quadros a seguir. O Quadro 1 sintetiza os achados pertinentes aos profissionais de Saúde da Família entrevistados.

Em relação às especialidades de cada uma das três profissões e ao trabalho multiprofissional em Saúde da Família, não fica claro o que os outros profissionais poderiam fazer em conjunto com o odontólogo que indicasse trabalho em conjunto. Há grande fragilidade no discurso deste profissional em comentar qualquer aspecto que não se refira ao ato clínico, o que faz pensar em quais os aspectos de Saúde Bucal são potenciais integradores com outras profissões.

Em termos da Enfermagem, há grande conteúdo para liderar grupos, mas não existe formação para o trabalho integrado com outros profissionais e profissões de saúde. É necessária a mudança da lógica do "sacrificar-se" para a lógica do cooperar sinergicamente.

A Medicina faz pensar a necessidade de "desmedicalizar o ensino e trabalho médico", ampliando a percepção da existência autônoma dos demais profissionais e demais atividades em saúde, além do foco biomédico e médico-centrado. 


\section{QuADRO 1}

Conteúdo interpretativo das falas dos profissionais de Saúde da Família entrevistados

\begin{tabular}{|c|c|c|c|c|c|}
\hline \multirow{2}{*}{$\begin{array}{c}\text { Categoria } \\
\text { profissional }\end{array}$} & \multicolumn{3}{|c|}{ Dimensão de análise } & & \multirow[b]{2}{*}{ Conteúdo interpretativo } \\
\hline & $\begin{array}{c}\text { Formação } \\
\text { universitária }\end{array}$ & $\begin{array}{c}\text { Atividade } \\
\text { em ESF }\end{array}$ & $\begin{array}{c}\text { Atividade } \\
\text { multiprofissional }\end{array}$ & & \\
\hline \multirow{2}{*}{ 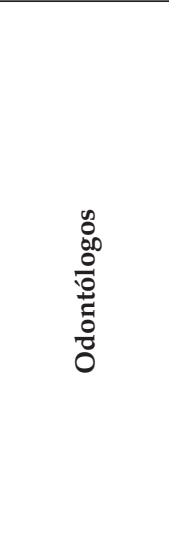 } & $\begin{array}{l}\text { Sem articulação } \\
\text { com outros } \\
\text { profissões }\end{array}$ & $\begin{array}{c}\text { Atividades } \\
\text { compartilhadas } \\
\text { com outros: } \\
\text { palestras e VD }\end{array}$ & $\begin{array}{l}\text { Divide espaço com } \\
\text { outros } \\
\text { Não há } \\
\text { compartilhar de } \\
\text { conhecimentos } \\
\text { Outros auxiliando } \\
\text { na clínica }\end{array}$ & Convergência & $\begin{array}{c}\text { A formação odontológica é pautada no } \\
\text { aspecto clínico, havendo falta de formação } \\
\text { para o trabalho com outros, além do } \\
\text { auxílio técnico, o que implicará problemas } \\
\text { para o trabalho em SP e no PSF. A lógica } \\
\text { do agrupamento de especialidades é a } \\
\text { conceituação de trabalho multiprofissional, } \\
\text { seja na prática da academia ou na realidade } \\
\text { dos serviços. }\end{array}$ \\
\hline & $\begin{array}{c}\text { Não trabalha no } \\
\text { PSF e SUS na } \\
\text { graduação }\end{array}$ & $\begin{array}{l}\text { Conhecimento } \\
\text { de Saúde Bucal: } \\
\text { privilégio do } \\
\text { odontólogo }\end{array}$ & $\begin{array}{l}\text { Outros auxiliando } \\
\text { na clínica } \\
\text { odontológica } \\
\text { O trabalho } \\
\text { multiprofissional } \\
\text { se restringe a } \\
\text { encaminhamento }\end{array}$ & Incoerências & $\begin{array}{c}\text { Sentem falta de formação para o trabalho } \\
\text { conjunto, mas tomam para si o conhecimento } \\
\text { em Saúde Bucal como privilégio. } \\
\text { Para eles, só existe no PSF o trabalho clínico } \\
\text { odontológico. }\end{array}$ \\
\hline \multirow[b]{2}{*}{ 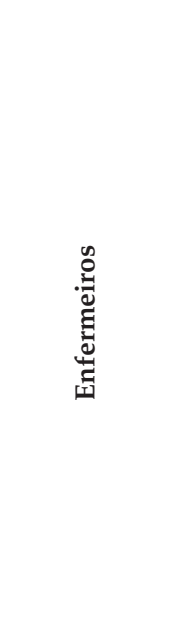 } & \multirow{2}{*}{$\begin{array}{l}\text { Relacionamento } \\
\text { interpessoal não } \\
\text { é trabalhado na } \\
\text { graduação } \\
\text { Conhecimentos } \\
\text { de enfermagem } \\
\text { são apenas do } \\
\text { enfermeiro }\end{array}$} & \multirow{2}{*}{$\begin{array}{l}\text { Foco no aspecto } \\
\text { clínico } \\
\text { Enfermeiro como } \\
\text { mãe de todos } \\
\text { Ninguém faz o } \\
\text { trabalho dele, } \\
\text { mas ele faz o } \\
\text { trabalho de todos } \\
\text { ("Bombril") }\end{array}$} & \multirow{2}{*}{$\begin{array}{c}\text { O trabalho } \\
\text { integrado não } \\
\text { acontece } \\
\text { Busca de objetivo } \\
\text { comum (jargão) } \\
\text { Trabalho integrado } \\
\text { cria dependência } \\
\text { entre os } \\
\text { profissionais }\left(^{*}\right) \\
\text { Aspecto clínico } \\
\text { fragmentado entre } \\
\text { profissionais e } \\
\text { sobreposto no ato }\end{array}$} & Convergência & $\begin{array}{l}\text { O enfermeiro é formado com foco de } \\
\text { "administrador de times de trabalho", ainda } \\
\text { de forma fragmentada e centralizando-se na } \\
\text { prática clínica. A lógica do agrupamento de } \\
\text { especialidades é a conceituação de trabalho } \\
\text { multiprofissional, seja na prática real da } \\
\text { academia ou na realidade dos serviços. }\end{array}$ \\
\hline & & & & Incoerências & $\begin{array}{l}\text { Há certa polarização entre "sacrificar-se" e } \\
\text { "dominar pela dívida do outro em função de } \\
\text { seu sacrifício". O trabalho multiprofissional, } \\
\text { como no PSF, é contrário a sua formação, } \\
\text { conforme exige equiparação de saberes e não } \\
\text { a lógica do domínio. Assim, dialogar saberes } \\
\text { é concorrer nesta visão, e foi forte o indício } \\
\text { de medo de perder controle sobre sua própria } \\
\text { ação, contrapondo-se ao jargão do "bom } \\
\text { trabalho em equipe pelo bem". }\end{array}$ \\
\hline \multirow{2}{*}{ 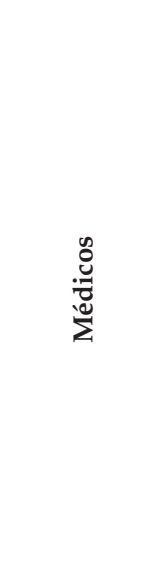 } & \multirow{2}{*}{$\begin{array}{c}\text { As diversas } \\
\text { profissões como } \\
\text { auxiliares } \\
\text { Não aprendeu a } \\
\text { integrar } \\
\text { O discurso } \\
\text { politicamente } \\
\text { correto existe na } \\
\text { academia }\end{array}$} & \multirow{2}{*}{$\begin{array}{c}\text { O verdadeiro } \\
\text { diagnóstico é do } \\
\text { médico. } \\
\text { Privilégio sobre a } \\
\text { prescrição. } \\
\text { Conhecimentos } \\
\text { básicos teóricos } \\
\text { são comuns, mas } \\
\text { a clínica não }\end{array}$} & \multirow{2}{*}{$\begin{array}{l}\text { Todos podem } \\
\text { ajudar o médico } \\
\text { Descrença na } \\
\text { possibilidade de } \\
\text { integração } \\
\text { Todos trabalham } \\
\text { em conjunto para } \\
\text { o bem comum } \\
\text { (jargão) } \\
\text { Cada um dar o seu } \\
\text { melhor (jargão) }\end{array}$} & Convergência & $\begin{array}{l}\text { Os outros saberes e profissionais servem ao } \\
\text { direcionamento e centralidade da medicina } \\
\text { junto à saúde. O teórico é comum a todos, } \\
\text { mas o clínico é diferente, com predominância } \\
\text { do médico. A lógica do agrupamento de } \\
\text { especialidades é a conceituação de trabalho } \\
\text { multiprofissional, seja na prática da academia } \\
\text { ou na realidade dos serviços. }\end{array}$ \\
\hline & & & & Incoerências & $\begin{array}{c}\text { Trabalho para a melhoria da sociedade e } \\
\text { com respeito às outras competências, desde } \\
\text { que os parâmetros sejam estabelecidos pelo } \\
\text { médico e o respeito às profissões submetidas } \\
\text { a competência médica. Incoerência com o } \\
\text { trabalho no PSF. }\end{array}$ \\
\hline
\end{tabular}


No que se refere a problemas para o trabalho multiprofissional em relação às três formações, os aspectos de saúde mental como algo comum à saúde são frágeis no discurso, valendo ainda a lógica especializada e do privilégio da psicologia, psiquiatria e educação neste campo. A ausência empírica de formação integrada e comum em termos de assistência para todos os profissionais de saúde é outro aspecto que emerge nestas entrevistas.

Daí, surgem as questões: "o outro é meu problema? o trabalho do outro é meu? meu trabalho é do outro? qual é meu espaço? o espaço comum é espaço de ninguém ou de todo mundo?". Saúde da Família, em teoria, é (ou deveria ser) um espaço comum, inclusive aos agentes comunitários e ao próprio usuário do sistema.

A seguir, apresentam-se os achados referentes aos fisioterapeutas e psicólogos (Quadro 2)

Comparando-se os achados para os profissionais em Saúde da Família com os dos fisioterapeutas entrevistados, em teoria, os primeiros apresentariam perspectivas diferentes, polarizadas e mais amplas que estes últimos. No entanto, o foco do trabalho multiprofissional apenas como sobreposição de espe- cialidades em um mesmo espaço, a falta de formação universitária para a integração com outras profissões e a dependência de valores individuais como fator de adesão profissional a um enfoque diferente do tradicional emergem com o mesmo conteúdo em ambos os grupos de profissionais. A prioridade ao ato clínico como objeto de trabalho também é similar.

No que se refere ao psicólogo, mesmo em nível de atenção secundária, a formação garante uma perspectiva ampla das potencialidades do trabalho genuinamente em equipe, divergindo da percepção dos profissionais de Saúde da Família em termos de uma visão pautada na integração e no explorar das potencialidades dos saberes. Nessa perspectiva, o trabalho em equipe multiprofissional deveria ser o produto dos conhecimentos e competências profissionais, mais do que a adição e sobreposição dos profissionais em um mesmo espaço. No entanto, a busca por território e por privilégios profissionais também emergiu entre os psicólogos, tanto quanto nos demais profissionais.

O Quadro 3 sintetiza os achados em termos de todos os profissionais, identificando dialeticamente os desafios a serem superados.

\section{QuAdro 2}

Conteúdo interpretativo das falas dos psicólogos e dos fisioterapeutas do hospital

\begin{tabular}{|c|c|c|c|c|c|}
\hline \multirow{2}{*}{$\begin{array}{l}\text { Categoria } \\
\text { profissional }\end{array}$} & \multicolumn{3}{|c|}{ Dimensão de análise } & \multirow{2}{*}{\multicolumn{2}{|c|}{ Conteúdo interpretativo }} \\
\hline & $\begin{array}{c}\text { Formação } \\
\text { universitária }\end{array}$ & $\begin{array}{l}\text { Atividade em } \\
\text { saúde }\end{array}$ & $\begin{array}{c}\text { Atividade } \\
\text { multiprofissional }\end{array}$ & & \\
\hline \multirow[b]{2}{*}{ 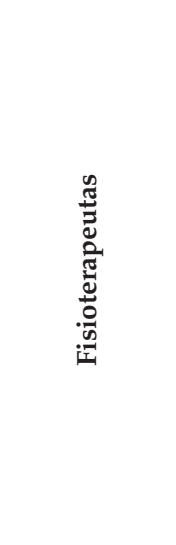 } & \multirow{2}{*}{$\begin{array}{l}\text { Multiprofissionalismo } \\
\text { se dá entre as } \\
\text { especialidades } \\
\text { fisioterapêuticas } \\
\\
\text { Houve práticas e } \\
\text { ensinamentos sobre } \\
\text { o trabalho em equipe } \\
\text { (fisioterapêutica) }\end{array}$} & \multirow[b]{2}{*}{$\begin{array}{c}\text { Aspectos clínicos } \\
\text { somente } \\
\text { Põe a atenção } \\
\text { emocional, } \\
\text { "psicológica", } \\
\text { como papel } \\
\text { de todos os } \\
\text { profissionais } \\
\\
\text { Atividades } \\
\text { integradas } \\
\text { dentro da } \\
\text { equipe, levando } \\
\text { ao bem-estar do } \\
\text { paciente }\end{array}$} & \multirow[b]{2}{*}{$\begin{array}{c}\text { A base da } \\
\text { integração está } \\
\text { na troca de } \\
\text { informações } \\
\text { Auxílio mútuo } \\
\text { no ambiente de } \\
\text { trabalho } \\
\text { É a junção do } \\
\text { trabalho de vários } \\
\text { profissionais } \\
\text { em busca de um } \\
\text { bem comum, que } \\
\text { é a melhora do } \\
\text { paciente (jargão) }\end{array}$} & Convergência & $\begin{array}{l}\text { Prioridade do ato clínico como objeto de } \\
\text { integração. }\end{array}$ \\
\hline & & & & Incoerências & $\begin{array}{l}\text { Equipe é sinônimo de integração de } \\
\text { especialidades fisioterapêticas. }\end{array}$ \\
\hline \multirow[t]{2}{*}{$\begin{array}{l}0 \\
0 \\
00 \\
0 \\
0 \\
0 \\
0 \\
0\end{array}$} & \multirow[t]{2}{*}{$\begin{array}{l}\text { Mérito grupal e não } \\
\text { individual, que pode } \\
\text { ser mais gratificante e } \\
\text { eficiente } \\
\text { Visão teórica do } \\
\text { trabalho em equipe é } \\
\text { aprendida }\end{array}$} & \multirow{2}{*}{$\begin{array}{c}\text { Auxílio à equipe } \\
\text { em problemas } \\
\text { amplos } \\
\text { Uma sondagem } \\
\text { mais técnica } \\
\text { de situações } \\
\text { de percepção } \\
\text { do estado } \\
\text { emocional é } \\
\text { privilégio do } \\
\text { psicólogo }\end{array}$} & \multirow[t]{2}{*}{\begin{tabular}{|} 
Trabalham de \\
maneira que \\
todos se sintam \\
importantes \\
Trocar informações \\
e desenvolver \\
atividades juntos \\
geraria um \\
trabalho integrado
\end{tabular}} & Convergência & $\begin{array}{l}\text { Existe teoria que sustenta as dinâmicas e } \\
\text { processos psicológicos do relacionamento } \\
\text { profissional em equipe, sendo que o } \\
\text { "se sentir importante" tem a ver com a } \\
\text { identidade de cada profissão. A ação sobre } \\
\text { projetos e objetos comuns permitiria um } \\
\text { trabalho integrado, mas não pela simples } \\
\text { sobreposição dos diversos saberes. }\end{array}$ \\
\hline & & & & Incoerências & As dimensões mentais são do psicólogo. \\
\hline
\end{tabular}




\section{QUADRO 3}

Produto interpretativo-dialético interprofissões a partir da análise dos conteúdos das falas tanto de profissionais de Saúde da Família, como dos profissionais da atenção hospitalar

\begin{tabular}{|c|c|c|c|c|}
\hline & \multicolumn{3}{|c|}{ Dimensão de análise } & \multirow{2}{*}{ Conteúdo interpretativo } \\
\hline & Formação & Atividade & Multiprofissional & \\
\hline $\begin{array}{l}\text { Convergências } \\
\text { interprofissionais }\end{array}$ & $\begin{array}{c}\text { Falta de formação } \\
\text { em objeto comum } \\
\text { aos profissionais que } \\
\text { trabalharão de maneira } \\
\text { integrada } \\
\text { Valores individuais } \\
\text { modulam o trabalho, e } \\
\text { não a formação }\end{array}$ & $\begin{array}{l}\text { Enfoque clínico } \\
\text { especializado } \\
\text { Sobreposição de } \\
\text { especialidades } \\
\text { não integradas, ao } \\
\text { invés de trabalho } \\
\text { mulriprofissional } \\
\text { integrado } \\
\text { Aspectos } \\
\text { interpessoais e } \\
\text { psicológicos do } \\
\text { trabalho são de } \\
\text { conhecimento dos } \\
\text { psicólogos }\end{array}$ & $\begin{array}{l}\text { É dividir o mesmo } \\
\text { espaço com outras } \\
\text { profissões, não } \\
\text { trabalhar de maneira } \\
\text { integrada } \\
\text { Possibilidade de troca } \\
\text { de conhecimentos, } \\
\text { mas não acontece } \\
\text { na prática. Cada um } \\
\text { fica no seu nicho de } \\
\text { conhecimentos } \\
\\
\text { Jargão: "vários } \\
\text { atuando pelo bem } \\
\text { comum" }\end{array}$ & 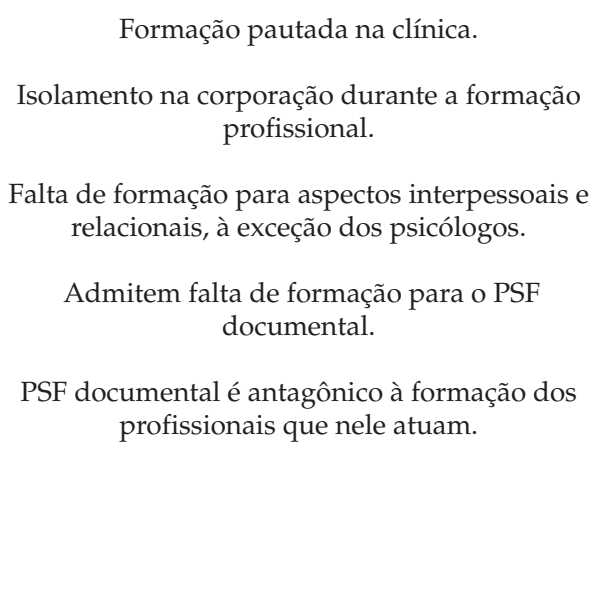 \\
\hline $\begin{array}{c}\text { Incoerências } \\
\text { interprofissionais }\end{array}$ & $\begin{array}{l}\text { Discurso politicamente } \\
\text { correto de integração, } \\
\text { mas com manutenção } \\
\text { de velhas relações } \\
\text { de poder entre as } \\
\text { profissões }\end{array}$ & $\begin{array}{l}\text { Todos priorizam } \\
\text { sua área clínica em } \\
\text { relação às demais }\end{array}$ & $\begin{array}{l}\text { Disputa pelo poder } \\
\text { sobre o outro } \\
\text { (auxiliando ou sendo } \\
\text { substituídos por...), } \\
\text { emblematizada } \\
\text { pela resistência ao } \\
\text { pensar em trabalho } \\
\text { múlti como se tornar } \\
\text { dependente do outro } \\
\text { Multiprofissionalismo } \\
\text { se restringe a } \\
\text { encaminhamento } \\
\text { "de espaço curto" }\end{array}$ & $\begin{array}{l}\text { Na vida profissional, o trabalho não é isolado } \\
\text { (tomando como foco a Saúde Pública). } \\
\text { Odontologia: isolamento conceitual. } \\
\text { Enfermagem: administrador dos outros. } \\
\text { Medicina: se vê como fundamento das } \\
\text { demandas dos outros. } \\
\text { Não tomam como caminho a integração para } \\
\text { superar os problemas, mas, sim, mantêm a } \\
\text { postura tradicional de disputa por privilégios } \\
\text { corporativos no ato clínico. }\end{array}$ \\
\hline Dialética & $\begin{array}{l}\text { Se há um discurso } \\
\text { oficial e nos currículos } \\
\text { de formação integrada } \\
\text { e para o trabalho no } \\
\text { PSF, por que se mantêm } \\
\text { as velhas estruturas? } \\
\text { São anos de } \\
\text { "reestruturação } \\
\text { curricular" no } \\
\text { Brasil. Por que ainda } \\
\text { continuam os mesmos } \\
\text { problemas? } \\
\text { A sociedade capitalista } \\
\text { é individualista. Por } \\
\text { que seria diferente com } \\
\text { o PSF? }\end{array}$ & $\begin{array}{c}\text { O foco na clínica não } \\
\text { promove indução } \\
\text { da formação que } \\
\text { prioriza sua área } \\
\text { de competência } \\
\text { em detrimento das } \\
\text { demais? }\end{array}$ & $\begin{array}{l}\text { Dividir o espaço com } \\
\text { outras profissões, em } \\
\text { um modelo que pede } \\
\text { integração na teoria, } \\
\text { mas na prática não } \\
\text { acontece } \\
\text { Agudiza as relações de } \\
\text { poder? } \\
\text { Mantém as relações de } \\
\text { poder estabelecidas? } \\
\text { Legitima as relações de } \\
\text { poder estabelecidas? } \\
\text { Mascara as relações de } \\
\text { poder estabelecidas? }\end{array}$ & $\begin{array}{c}\text { A academia é um espaço artificial em que } \\
\text { se pensa a realidade? Ou ela é a legitimação } \\
\text { de um modelo que não foi superado na prática } \\
\text { e, como tal, cumpre sua função? } \\
\text { Ou seja: a academia está formando para } \\
\text { o SUS de fato, que é totalmente antagônico } \\
\text { ao SUS idealizado? } \\
\text { O capitalismo é pano de fundo das relações. } \\
\text { Por que seria diferente no PSF? } \\
\text { Os valores individuais explicam estes } \\
\text { paradoxos? } \\
\text { O Estado coloca a responsabilidade no } \\
\text { profissional ou ela é do profissional mesmo? }\end{array}$ \\
\hline
\end{tabular}


Uma vez que os entrevistados são formados na universidade para o trabalho clínico-especializado e privilegiado de cada corporação profissional, a proposta do trabalho integrado e integrador em Saúde da Família vai ser tomada por eles como dependente de vontade individual. Mesmo os aspectos psicológicos do trabalho serão pensados segundo a mesma lógica, o que sustenta a afirmação de que são pertinentes ao profissional psicólogo.

Em decorrência, no confronto com o espaço comum em Saúde da Família, não haverá integração e compartilhamento do território, mas, sim, divisão, faltando troca de conhecimentos, apesar do senso comum de que o trabalho multiprofissional acontece quando vários atuam para o bem comum. Inclusive, há certa resistência implícita nos discursos, que reafirmam o termo "dependência" como consequência do trabalho multiprofissional, o que é diferente da construção conjunta, conduzindo à ideia de um trabalho multiprofissional como o "encaminhar" aos outros profissionais e seus saberes específicos quando se identifica essa necessidade.

Com base no conhecimento aprendido/treinado na universidade e com a estruturação do processo de trabalho de fato no PSF, o odontólogo permanece imerso na perspectiva odontológica da assistência à saúde, sem articulação com as demais áreas; o enfermeiro, como centralizador dos aspectos práticos e administrativos da equipe de saúde; e o médico adotando a postura de centro do processo de trabalho, em que os demais profissionais suplementam suas atividades. Estas ideias que emergem do campo empírico retomam fundamentos mais amplos e corporativos de privilégio de atos clínicos.

E o PSF, conforme idealizado nos documentos oficiais, tem um cenário distante do que acontece na prática, nos aspectos abordados no presente artigo.

Na medida em que os entrevistados são indivíduos antes de serem profissionais, há que se ressaltar que estão imersos em relações sociais que têm como pano de fundo o capitalismo, a despeito da horizontalidade de relações que o PSF documental exige - e esta horizontalidade não se aplica apenas ao relacionamento multiprofissional. É mais profunda: se aplica à equiparação entre os profissionais e o usuário do sistema, a exemplo dos mecanismos legais de planejamento local e do controle social existentes.

Paralelamente, o SUS toma a saúde como um direito do cidadão. No entanto, mesmo após a reestruturação curricular dos três cursos que integram a ESF, ainda perduram os problemas da formação para o trabalho multiprofissional. Uma característica que dificulta este processo talvez seja a lógica fragmentadora que os sujeitos denunciaram ao afirmar que não aprenderam a trabalhar com outras profissões, até mesmo porque os cursos não possuem disciplinas de trabalho e objeto comuns.

Em outra perspectiva de análise, não há na literatura trabalhos que investiguem as relações de poder entre as corporações e respectivas profissões no âmbito de trabalho em Saúde da Família, o que dificulta a construção de caminhos para superar a formação fragmentada e desagregadora.

É preciso haver uma reorientação do trabalho em Saúde da Família, em espaços que abarquem dimensões e objetos de trabalho comuns, assim como peculiaridades das competências profissionais, com a definição clara de peculiaridades profissionais no processo de trabalho em ESF, assim como de objetos e processos de trabalho comuns.

Estas questões sobre a regulação da organização e processo de trabalho em Saúde da Família convergem para as questões anteriores sobre "poder", "status" e "influência" dos profissionais na sociedade, quadro claramente antissinérgico e que se reveste de peculiaridades tais como a remuneração desigual para um trabalho que é horizontal.

\section{DISCUSSÃO}

Vale lembrar que a ESF se originou na reformulação das prioridades do Ministério da Saúde com relação à Atenção Primária, sendo proposta como caminho para reorganização da atenção à saúde no Brasil, com vistas a tornar efetivo o Sistema Único de Saúde (SUS) ${ }^{12}$. Compromete-se a prestar atenção pautada no atendimento integral, contínuo, com equidade e resolutividade através de prática humanizada e desenvolver ações de prevenção e promoção de Saúde.

Parte de um processo de trabalho em equipe multiprofissional, que deve conhecer as famílias do território sob sua abrangência, identificar problemas de saúde e situações de risco desta comunidade, exercer planejamento local com base e imerso na realidade que planeja, pautando-se no rompimento da lógica biomédico-curativo-medicalizada e se voltando para um enfoque em ações educativas e intersetoriais, fazendo valer o princípio da integralidade na atenção, em um continuum com os demais níveis de assistência, buscando criar vínculos entre os profissionais e usuários, através da corresponsabilização na resolução dos problemas de saúde ${ }^{6}$.

O usuário deve ser ressignificado no processo de trabalho, dimensão complexa ao dar ênfase à coparticipação no planejamento da assistência, com enfoque na valorização de saberes e do entorno sociocultural, em um gradativo processo de horizontalização e humanização da relação profissional de saúde-usuário ${ }^{6}$.

Evidencia-se, assim, a abordagem ampliada da atenção em saúde e da complexidade inerente, podendo ser conside- 
rado um modelo contra-hegemônico ao modelo flexneriano/ biomédico, que valoriza apenas saberes oriundos da academia e a supremacia/dominação do poder do profissional sobre a saúde do usuário, em que há ênfase no fenômeno biológico e distanciamento das dimensões sociais, psicológicas e comportamentais implicadas na doença. A concepção mecanicista em saúde lhe é inerente, sendo o corpo como uma máquina composta por partes inter-relacionadas, e a doença se reduz a uma irregularidade no processo de funcionamento, valorizando-se a formação clínica e subespecialidades, deixando à margem o aspecto subjetivo e relacional do encontro com o paciente ${ }^{13,14}$.

Apesar de a Saúde da Família constituir um modelo de atenção primária que prima pela visão complexa do usuário, a formação universitária de seus profissionais ainda se pauta na visão fragmentária, reduzida ao âmbito da disciplinaridade (anatomia, patologia, genética, farmacologia, economia, sociologia, etc. $)^{1,15}$

A dicotomia entre o identificar da importância e o silêncio sobre a operacionalização do trabalho em ESF pode constituir um emblema da existência de problemas para a formação com ênfase no SUS, com os sujeitos silenciando sobre como atuariam de acordo com os princípios norteadores deste. Uma vez que aprenderam apenas os aspectos técnicos da profissão e não como se articular com outras profissões, com que dividirão espaço nos Serviços, a enfocar a vida vivida dos pacientes e muito menos a intersetorialidade em Saúde, a formação universitária por si só não lhes possibilitará atuar desta forma ${ }^{1}$.

Existem deficiências evidenciadas que não se referem apenas ao debate histórico das pedagogias do "aprender fazendo". Em sentindo amplo, também tratam da delicada questão política própria da universidade pública brasileira: formar profissionais no âmbito de uma instituição pública com enfoque diferente da necessidade do serviço público e da coletividade ${ }^{1}$.

Estas profissões apresentam um longo processo de qualificação e capacitação técnico-intelectual, além do que o processo de trabalho envolve especificidades do campo do cuidado à saúde, em especial o fato de que a prestação de serviços em saúde não se dá diretamente sobre um objeto inerte, mas, sim, sobre um ser humano que requer cuidados e, como tal, apresenta subjetividade e complexidade societárias, depreendendo-se que a utilização dos serviços de saúde tem características diferentes para cada estrato social e para cada sociedade ${ }^{3}$.

Neste sentido, muitas vezes, os profissionais optam pelo trabalho em Saúde da Família mais pela disponibilidade de postos de serviço do que propriamente pela ideologia da ESF.

A literatura aponta que as características de profissional liberal clássico fundamentam a escolha da profissão pelos acadêmicos que ingressam na universidade ${ }^{16}$, apesar de que a prática liberal se torna gradativamente "prática assalariada, onde a liberdade de atuação profissional é limitada, uma vez que passa a ser regida por uma lógica de produção"16(p.12). Esta visão também é reforçada por outros autores ${ }^{17,18}$, que sustentam que a formação acadêmica em saúde é direcionada para o exercício profissional apoiado no pensamento neoliberal, postura superficial e reducionista em relação ao pano de fundo que reveste a questão. $\mathrm{O}$ esgotamento das possibilidades para a prática liberal é multicausal e complexa, com diversos aspectos, como a aguda e crescente perda de poder aquisitivo da classe média ${ }^{17}$ e o elevado número de profissionais que ingressa anualmente no mercado de trabalho ${ }^{16-18}$.

Na categoria médica, Donnangelo ${ }^{19}$ discute que o assalariamento é fruto de mudanças estruturais da sociedade, com consequente redefinição das formas sociais de trabalho dos profissionais. No seio destas alterações está a perda da propriedade e do controle dos meios de produção por parte dos produtores diretos dos serviços, o que origina nova divisão do trabalho entre os profissionais da categoria, "resultante de novas formas de distribuição e concentração daqueles meios e que permite pensar os produtores como tendencialmente assalariados e não assalariados"19 (p.53-4).

Estudos nesta direção serão importantes para desvelar as consequências do trabalho em nova configuração, tanto para os trabalhadores como para os pacientes, numa perspectiva segundo a qual, no pensamento de Foucault, podem ser pensados como corpos dóceis e submissos à lógica da sociedade capitalista e do capital ${ }^{20}$.

Quanto às dinâmicas das relações de poder entre as profissões e corporações de saúde, há que se considerar que o processo de trabalho em saúde se fundamenta na dinâmica social externa a este setor, mantendo-se subjacente a lógica na qual o poder regulador médico, disciplinador e biopolítico modula as relações entre os cidadãos ${ }^{21}$.

Em termos da corporação médica, há certo entendimento de que há descaracterização do trabalho médico como idealizado, principalmente nos componentes que não dependem de tecnologia, tais como anamnese, exame físico e aconselhamento ${ }^{22}$. Mas esta situação gera queixa dos profissionais, como perda do status profissional, para o qual a confiabilidade dos pacientes é fundamental ${ }^{22}$.

Outra consideração se refere à questão do direito à saúde e do novo modelo de atenção em Saúde da Família. Silvia e Waissman ${ }^{23}$ defendem que as políticas públicas em saúde ainda se estabelecem no Brasil de maneira tópica, o que compromete o processo de atingir objetivos maiores em termos dos direitos sanitários fundamentais garantidos na Constituição, a despeito da importância e relevância de todas estas políticas. 
Como consequência do exposto no presente trabalho, fica o questionamento de como ter um profissional de saúde em um modelo focado na prática coletiva na sociedade capitalista atual, uma vez que, para se cogitar sobre o perfil de profissão que se quer, é necessária uma reflexão sobre qual sociedade se deseja, pois, antes de serem profissionais de Saúde da Família, trata-se de seres sociais e cidadãos, modulados e moduladores da sociedade em que vivem.

\section{CONSIDERAÇÕES FINAIS}

Como mudar um processo que envolve cidadania (e, neste caso, direito à saúde através do PSF), sem mudar a sociedade e suas relações sociais? Indo mais a fundo: a reforma sanitária está completa sem mudança da sociedade? É o SUS/PSF um risco para o capitalismo?

Em vista dos achados do presente trabalho, alguns caminhos para superação podem ser pensados.

Há que haver reorientação curricular efetiva e integrada entre os cursos de saúde, com foco em objetos e objetivos comuns, fundamentados no SUS idealizado.

Paralelamente, tem-se a necessidade de reorientar o trabalho na ESF em espaços que abarquem dimensões e objetos de trabalho comuns, assim como peculiaridades das competências profissionais, partindo do multidisciplinar para o trabalho interdisciplinar. Também em termos trabalhistas há que se pensar. Se o médico, o dentista e o enfermeiro são profissionais altamente qualificados, por que no Amazonas o médico tem remuneração de $R \$ 9.000,00$, enquanto o enfermeiro e o odontólogo menos da metade desse montante? Como se relacionar horizontalmente se até o salário é desigual?

Com exceção do discurso dos psicólogos, a percepção dos profissionais depõe sobre a fragilidade na construção do projeto de intervenção conjunta, necessário principalmente em nível da Estratégia de Saúde da Família, apresentando a perspectiva de que o trabalho multiprofissional se dá apenas nos aspectos técnicos, e não na lógica que rege o processo de trabalho. Ou se muda a Saúde da Família e se admite que ela é simplesmente como seus modelos antecessores (pautados no mercado e nas tradições entre as profissões de saúde) ou se transformam os processos e os profissionais radicalmente.

\section{Aprovação Ética}

Comitê de Ética em Pesquisa com Seres Humanos da Universidade Federal de Santa Catarina, Projeto "Saúde da Família no interior do Estado do Amazonas e a operacionalização dos princípios do SUS" (Protocolo ético 121/2009).

Apoio: Auxílio financeiro a projeto de pesquisa - CNPq/ Edital Universal 2008 (Processo CNPq 470.165/2008-1).

\section{REFERÊNCIAS}

1. Moretti-Pires RO. Complexidade em Saúde da Família e formação do futuro profissional de saúde. Interface Comun.Saúde Educ. 2009;13(13):153-66.

2. Elias PE. Estado e saúde: os desafios do Brasil contemporâneo. São Paulo Perspect. 2004;18(3):41-6.

3. Brasil. Ministério da Saúde. Secretaria de Assistência à Saúde. Saúde da família: uma estratégia para a reorientação do modelo assistencial. Brasília: Ministério da Saúde; 1997.

4. Vasconcelos CM. Paradoxos da mudança no SUS. Campinas, SP; 2005. Doutorado [Tese] — Universidade Estadual de Campinas.

5. Machado MH. Trabalhadores da saúde e sua trajetória na reforma sanitária. In: Lima NT, Gerschman S, Edler FC, Manuel Suárez J, org. Saúde e democracia: história e perspectivas do SUS. Rio de Janeiro: Fiocruz; 2005. p.257-81.

6. Araújo MBS, Rocha PM. Trabalho em equipe: um desafio para a consolidação da estratégia de saúde da família. Ciênc Saude Coletiva. 2007;12(2):455-64.

7. Crevelim MA, Peduzzi M. A participação da comunidade na equipe de saúde da família. Como estabelecer um projeto comum entre trabalhadores e usuários? Ciênc Saude Coletiva. 2005; 10(2):323-31

8. Silva IZQJ, Trad LAB. O trabalho em equipe no PSF: investigando a articulação técnica e a interação entre os profissionais. Interface Comun.Saúde Educ. 2005;9(16):25-38.

9. Brasil. Ministério da Saúde. Portaria no 648/GM, de 28 de março de 2006. Aprova Política Nacional de Atenção Básica, estabelecendo a revisão de diretrizes e normas para a organização da Atenção Básica para o Programa Saúde da Família (PSF) e o Programa Agentes Comunitários de Saúde (PACS).

10. Minayo MCS. Hermeneutica-dialética como caminho do pensamento social. In: Minayo MCS, Deslandes SF. Caminhos do pensamento: epistemologia e método. Rio de Janeiro: Fiocruz; 2002. p.83-107.

11. Minayo MCS. O desafio do conhecimento: pesquisa qualitativa em saúde. Rio de Janeiro: Hubitec-Abrasco; 1999.

12. Mendonça MHM, Vasconcellos MM, Vianna ALA. Atenção Primária à Saúde no Brasil. Cad Saúde Pública. 2008;24(Sup 1):S4-S5.

13. Marco MA. Do modelo biomédico ao modelo biopsicossocial: um projeto de educação permanente. Rev Bras Educ Med. 2006; 30(1):60-72.

14. Koifman L. O modelo biomédico e a reformulação do currículo médico da Universidade Federal Fluminense. Hist Cienc Saude Manguinhos. 2001;8(1):48-70. 
15. Moretti-Pires RO. O Médico para Saúde da Família no Estado do Amazonas: lacunas na formação, lacunas na atenção. Rev Bras Educ Med. 2009;33(3):428-36.

16. Mello ACF. Mercado de trabalho, política de saúde bucal e formação profissional: o que pensam estudantes de odontologia. Rio de Janeiro; 2004. Mestrado [Dissertação] - Universidade Federal do Rio de Janeiro.

17. Machado MH, Belisário SA. Os médicos e o mercado de trabalho. In: Canesqui AM, org. Ciências Sociais e Saúde para o ensino médico. São Paulo: Hucitec, Fapesp; 2000. p 99-110.

18. Moretti-Pires RO. O pensamento crítico social de Paulo Freire sobre humanização e o contexto da formação do enfermeiro, do médico e do odontólogo. Ribeirão Preto, SP; 2008. Doutorado [Tese] — Universidade de São Paulo.

19. Donnangelo MCF. O médico e o mercado de trabalho. São Paulo; 1972. Doutorado [Tese] — Universidade de São Paulo.

20. Foucault M. Vigiar e Punir. Petrópolis: Vozes; 2004.

21. Bialakowsky AL, Franco DE, Patrouilleau M, Bardi N, Lusnich C, Zaleschi C, Grima JM. Uma sociologia do trabalho contrastada. Tempo Soc. 2006;18(1):241-63.
22. Bulcao LG, Sayd JD. As razões da escola médica: sobre professores e seus valores. Os valores dos médicos e os impasses da escola médica. Physis. 2003;13(1):11-38.

23. Silva PF, Waissmann W. Normatização, o Estado e a saúde: questões sobre a formalização do direito sanitário. Ciênc Saude Coletiva. 2005;10(1):237-44.

\section{CONTRIBUIÇÃO DOS AUTORES}

Ambos os autores participaram de todas as fases do projeto, elaboração e finalização do presente artigo

\section{CONFLITO DE INTERESSES}

Declarou não haver.

\section{ENDEREÇO PARA CORRESPONDÊNCIA}

Rodrigo Otávio Moretti-Pires

Departamento de Saúde Pública — Centro de Ciências da Saúde - UFSC

Campus Universitário - Trindade - Florianópolis

CEP. 88040-970 SC

E-mail: rodrigo.moretti@pq.cnpq.br 